Selected papers from the International Scientific and Practical Conference "Basic Science for Practical Medicine - 2021", 15-18 September 2021, Elbrus v., Russia, http://uniid.kbsu.ru/medicine2021

Original article

\title{
In vitro antimicrobial activity of layered silicate materials
}

\author{
Madina Kh. Shpagina, Umalat I. Dugarov, Seda S. Khashirova, Amina S. Vindizheva, Elena B. Barokova, \\ Larisa B. Tlapshokova, Svetlana Yu. Khashirova, Zaira F. Kharaeva
}

Kabardino-Balkarian State University, Nalchik, Russia

Received 1 October 2021, Revised 26 November 2021, Accepted 12 December 2021

C 2021, Russian Open Medical Journal

\begin{abstract}
Objective - to assess the presence of a direct antimicrobial effect of natural minerals (ammonite; montmorillonite of the Azerbaijani deposit; calcium montmorillonite, or light clay, and sodium montmorillonite, or dark clay, of the Gerpegezh deposit in Kabardino-Balkaria; serpentinite) against strains of Staphylococcus aureus, Escherichia coli and yeast-like Candida fungi.

Material and Methods - The antimicrobial activity was investigated by qualitative and quantitative methods; the methods of $\mathrm{X}$-ray diffraction and $X$-ray fluorescence analysis were used to assess the chemical composition of samples of natural minerals. The results were statistically processed.

Results - We established that ammonite, montmorillonite of Azerbaijani origin and serpentinite did not have a direct antimicrobial effect against the studied cultures of bacteria and fungi (S. aureus, E. coli, Candida albicans). The growth of S. aureus was suppressed by calcium and sodium montmorillonite from the Gerpegezh deposit. Sodium montmorillonite had the strongest antibacterial effect, and its dosedependent effect was revealed. According to the data of X-ray fluorescence analysis, in the structure of, trivalent iron and oxides of manganese and titanium predominated in the samples of dark Gerpegezh clay with a more pronounced anti-staphylococcal effect.

Conclusion - Our study demonstrated the possibilities and limitations of using various samples of layered silicate minerals for antibacterial solutions. The spectrum of antimicrobial activity largely depends on the unique composition of mineral complexes. Samples with a high content of iron(III) can be considered promising in the development of natural antimicrobial preparations.
\end{abstract}

Keywords: montmorillonite, antimicrobial effect, Staphylococcus aureus, Escherichia coli, Candida albicans.

Cite as Shpagin MKh, Dugarov UI, Khashirova SS, Vindizheva AS, Barokova EB, Tlapshokova LB, Khashirova SYu, Kharaeva ZF. In vitro antimicrobial activity of layered silicate materials. Russian Open Medical Journal 2021; 10: e0422.

Correspondence to Zaira F. Kharaeva. Address: 59a Lenin Prospect, Apt. 9, Nalchik 360022, Kabardino-Balkarian Republic, Russia. Phone: +79287089166.

E-mail: irafe@yandex.ru.

\section{Introduction}

The problem of treating bacterial infectious diseases, despite constantly developing varieties of nonmedicamentous exposure and emergence of new antibacterial pharmaceutical drugs, remains highly relevant $[1,2]$. In recent decades, there was a significant increase in the resistance of pathogens of infectious diseases to antibiotics, whereas there was a simultaneous increase in the number of patients with suppurative-inflammatory diseases and in the percentage of identified bacteria carriers [3, 4]. An urgent problem is also the complicated course of many infectious diseases: year after year, an increasing number of patients with atypical disease course and complications is recorded [5-7]. In many countries, the spread of Klebsiella pneumoniae and Acinetobacter baumanii strains, resistant to penicillin and fourthgeneration cephalosporins, is noted [8]. More than $90 \%$ of Staphylococcus aureus strains, isolated from patients with sepsis, are methicillin-resistant [9]. This problem has become especially acute during the coronavirus pandemic, when broad-spectrum antibiotics and reserve group antibiotics are massively used to treat patients with community-acquired pneumonia [10].

In connection with the current situation, it is urgent to search for, and approbate, non-antibiotic methods of therapy and prevention of bacterial infections, including the use of natural mineral complexes. Some publications mentioned using the samples of layered silicate complexes as an alternative and/or supplementary method for treating bacterial infectious diseases $[11,12]$. Bentonite clays constituent valuable mineral-based raw materials. Due to its binding and sorption properties, swelling tendency and high thermal stability, bentonite has become an indispensable raw material in various industries. In total, there are over 200 areas of bentonite use, including those in the medical field $[13,14]$. However, the properties of natural mineral complexes are quite different, and therefore, general recommendations cannot be developed, and additional research is needed on the properties of each local deposit. 
Table 1. Staphylococcus aureus E-1 growth inhibition zone vs. aqueous solution application at various concentrations*, mm

\begin{tabular}{|c|c|c|c|c|c|}
\hline \multirow[b]{2}{*}{ Sample, concentration } & \multicolumn{5}{|c|}{ Growth inhibition zone diameter, $\mathrm{mm}$} \\
\hline & $\begin{array}{l}\text { Immediately after } \\
\text { solution preparation }\end{array}$ & $24 \mathrm{hrs}$. & $48 \mathrm{hrs}$. & 72 hrs. & $\begin{array}{l}\text { Lysis zone after } 24 \\
\text { vs. } 72 \text { hrs. }\end{array}$ \\
\hline Ammonite, $1 \mathrm{mg} / \mathrm{L}$ & No lysis zone & No lysis zone & No lysis zone & No lysis zone & - \\
\hline Ammonite, $5 \mathrm{mg} / \mathrm{L}$ & No lysis zone & No lysis zone & No lysis zone & No lysis zone & - \\
\hline Ammonite, $10 \mathrm{mg} / \mathrm{L}$ & No lysis zone & No lysis zone & No lysis zone & No lysis zone & - \\
\hline Montmorillonite of Azerbaijani deposit, $1 \mathrm{mg} / \mathrm{mL}$ & $2 \pm 1$ & $2 \pm 1$ & $2 \pm 1$ & $2 \pm 1$ & $p=1.0$ \\
\hline Montmorillonite of Azerbaijani deposit, $5 \mathrm{mg} / \mathrm{mL}$ & $2 \pm 1$ & $3 \pm 1$ & $3 \pm 1$ & $3 \pm 1$ & $p=1.0$ \\
\hline Montmorillonite of Azerbaijani deposit, $10 \mathrm{mg} / \mathrm{mL}$ & $4 \pm 1$ & $5 \pm 1^{1}$ & $5 \pm 1^{1}$ & $5 \pm 1^{1}$ & $\mathrm{p}=1.0$ \\
\hline Sodium montmorillonite of Gerpegezh deposit, $1 \mathrm{mg} / \mathrm{mL}$ & $6 \pm 1$ & $7 \pm 1$ & $7 \pm 1$ & $7 \pm 1$ & $p=1.0$ \\
\hline Sodium montmorillonite of Gerpegezh deposit, $5 \mathrm{mg} / \mathrm{mL}$ & $8 \pm 1^{1}$ & $9 \pm 1^{1}$ & $11 \pm 1^{1}$ & $10 \pm 1^{1}$ & $p=0.53$ \\
\hline Sodium montmorillonite of Gerpegezh deposit, $10 \mathrm{mg} / \mathrm{mL}$ & $11 \pm 1,2$ & $12 \pm 1^{1,2}$ & $13 \pm 1^{1}$ & $12 \pm 1^{1}$ & $p=1.0$ \\
\hline Calcium montmorillonite of Gerpegezh deposit, $1 \mathrm{mg} / \mathrm{mL}$ & $4 \pm 1$ & $7 \pm 1$ & $7 \pm 1$ & $7 \pm 1$ & $p=1.0$ \\
\hline Calcium montmorillonite of Gerpegezh deposit, $5 \mathrm{mg} / \mathrm{mL}$ & $7 \pm 1^{1}$ & $9 \pm 1^{1}$ & $10 \pm 1^{1}$ & $9 \pm 1^{1}$ & $\mathrm{p}=1.0$ \\
\hline Calcium montmorillonite of Gerpegezh deposit, $10 \mathrm{mg} / \mathrm{mL}$ & $11 \pm 1^{1,2}$ & $11 \pm 1^{1,2}$ & $13 \pm 1^{1,2}$ & $11 \pm 1^{1,2}$ & $p=1.0$ \\
\hline Serpentinite, $1 \mathrm{mg} / \mathrm{mL}$ & No lysis zone & No lysis zone & No lysis zone & No lysis zone & - \\
\hline Serpentinite, $5 \mathrm{mg} / \mathrm{mL}$ & No lysis zone & No lysis zone & No lysis zone & No lysis zone & - \\
\hline Serpentinite, $10 \mathrm{mg} / \mathrm{mL}$ & No lysis zone & No lysis zone & No lysis zone & No lysis zone & - \\
\hline
\end{tabular}

${ }^{*}$ antimicrobial activity was assessed at $0,24,48$ and $72 \mathrm{hrs}$. after solution preparation. ${ }^{1} \mathrm{p}<0.05$ compared with solutions of $1 \mathrm{mg} / \mathrm{mL} ;{ }^{2} \mathrm{p}<0.05 \mathrm{compared}$ with solutions of $5 \mathrm{mg} / \mathrm{mL}$.

Table 2. Chemical composition of sodium and calcium montmorillonites of Gerpegezh deposit (in \% of dry matter)

\begin{tabular}{|c|c|c|c|c|c|c|}
\hline \multirow{2}{*}{ Composition } & \multicolumn{3}{|c|}{ Sodium (dark) clay } & \multicolumn{3}{|c|}{ Calcium (light) clay } \\
\hline & $\min$ & $\max$ & mean & $\min$ & $\max$ & mean \\
\hline $\mathrm{SiO}_{2}$ & 51.8 & 69.4 & $61.6 \pm 8.5$ & 46.5 & 56.7 & $51.1 \pm 5.0$ \\
\hline $\mathrm{A}_{2} \mathrm{O}_{3}$ & 9.3 & 15.7 & $12.4 \pm 3.3$ & 12.1 & 15.5 & $13.5 \pm 2.0$ \\
\hline $\mathrm{TiO}_{2}$ & 0.59 & 1.65 & $1.10 \pm 0.55^{1}$ & 0.50 & 0.85 & $0.69 \pm 0.16$ \\
\hline $\mathrm{FeO}$ & 1.08 & 2.25 & $1.3 \pm 0.9$ & 0.40 & 2.30 & $1.13 \pm 1.17$ \\
\hline $\mathrm{Fe}_{2} \mathrm{O}_{3}$ & 4.7 & 9.1 & $6.8 \pm 1.9^{1}$ & 2.5 & 6.8 & $4.4 \pm 2.4$ \\
\hline $\mathrm{P}_{2} \mathrm{O}_{5}$ & 0.04 & 0.29 & $0.1 \pm 0.9$ & 0.05 & 0.15 & $0.08 \pm 0.07$ \\
\hline $\mathrm{MnO}$ & 0.40 & 0.94 & $0.7 \pm 0.2^{1}$ & 0.07 & 0.55 & $0.31 \pm 0.24$ \\
\hline $\mathrm{CaO}$ & 3.1 & 10.3 & $6.2 \pm 4.1$ & 3.3 & 15.9 & $8.1 \pm 7.8$ \\
\hline $\mathrm{MgO}$ & 1.0 & 2.9 & $2.1 \pm 1.8$ & 1.8 & 3.5 & $2.6 \pm 0.9$ \\
\hline $\mathrm{K}_{2} \mathrm{O}$ & 1.7 & 3.3 & $2.3 \pm 1.0$ & 2.3 & 3.4 & $3.0 \pm 0.4$ \\
\hline $\mathrm{Na}_{2} \mathrm{O}$ & 0.3 & 3.2 & $1.7 \pm 1.3$ & 0.4 & 1.9 & $1.2 \pm 0.7$ \\
\hline $\mathrm{SO}_{3}$ & 0.10 & 1.08 & $0.5 \pm 0.3$ & 0.20 & 0.65 & $0.39 \pm 0.26$ \\
\hline $\mathrm{F}$ & 0.061 & 0.078 & $0.069 \pm 0.009$ & 0.010 & 0.022 & $0.015 \pm 0.007$ \\
\hline $\mathrm{Cu}$ & 0.007 & 0.011 & $0.009 \pm 0.002$ & 0.005 & 0.007 & $0.006 \pm 0.001$ \\
\hline $\mathrm{Zn}$ & 0.010 & 0.013 & $0.012 \pm 0.001$ & 0.011 & 0.014 & $0.012 \pm 0.002$ \\
\hline $\mathrm{PI}$ & 0.005 & 0.005 & $0.005 \pm 0.000$ & 0.005 & 0.005 & $0.005 \pm 0.00$ \\
\hline $\mathrm{Cd}$ & 0.001 & 0.001 & $0.001 \pm 0.000$ & 0.001 & 0.001 & $0.001 \pm 0.00$ \\
\hline Co & 0.004 & 0.005 & $0.0045 \pm 0.0005$ & 0.003 & 0.005 & $0.004 \pm 0.001$ \\
\hline
\end{tabular}

${ }^{1} \mathrm{p}<0.05$ for sodium montmorillonite vs. calcium montmorillonite.

The objective of our study was to assess the direct antimicrobial effect of natural minerals (ammonite; montmorillonite of the Azerbaijani deposit; calcium montmorillonite, or light clay, and sodium montmorillonite, or dark clay, of the Gerpegezh deposit in Kabardino-Balkaria; and serpentinite) against strains of Staphylococcus aureus, Escherichia coli and yeast-like Candida fungi.

\section{Material and Methods}

The following samples of natural minerals were examined: ammonite, montmorillonite of the Azerbaijan deposit, calcium (light clay) and sodium (dark clay) montmorillonites of the Gerpegezh deposit in Kabardino-Balkaria, and serpentinite. Correct identification of each mineral was confirmed by the method of $X$ ray phase and $\mathrm{X}$-ray fluorescence analyses at the Center for Collective Equipment Use, X-ray Diagnostics of Materials, Kabardino-Balkarian State University (KBSU).

\section{Studying antibacterial effects of natural minerals}

The antibacterial effect in the samples of natural minerals was tested on bacterial cultures of S. aureus VD-1 and E-1, E. coli, and yeast-like fungus (Candida albicans). Bacterial cultures were isolated from the mucous membranes of the oral cavity, nasopharynx, gastrointestinal tract of patients with suppurativeinflammatory diseases (rhinopharyngitis, tonsillitis, stomatitis, and enterocolitis).

Isolated from the oral mucosa, S. aureus VD-1 was the strain with high antibiotic resistance to benzylpenicillin, erythromycin, ampicillin, neomycin. S. aureus $E-1$ was isolated from the tonsils; it showed resistance to benzylpenicillin. E. coli strain was isolated from the gastrointestinal tract, lactose-negative, opportunistic. C. albicans was isolated from the oral mucosa. Identification of isolated pure cultures of microorganisms was carried out on the basis of their morphological, cultural, biochemical characteristics and via using the mass spectrometric method on MALDI-TOF system (Microflex, Bruker). 
Antimicrobial activity has been investigated in staged experiments.

Stage 1 represented a qualitative study of the antimicrobial effect presence in the course of applying the pastes prepared by diluting a dry powdered $5 \mathrm{~g}$ sample of a mineral with sterile water. Pastes were applied to the surface of a Petri dish with Meat Peptone Broth (MPB) or Sabouraud agar (when working with Candida albicans), on which microorganism cultures were preliminarily inoculated and evenly distributed at a concentration of $10^{9} \mathrm{~b} / \mathrm{mL}$.

Stage 2 included the study of the antimicrobial effect of watersoluble salts and of a dose-dependent effect presence. The solutions were prepared with different concentrations of the studied minerals $(2 \mathrm{mg} / \mathrm{mL}, 5 \mathrm{mg} / \mathrm{mL}, 10 \mathrm{mg} / \mathrm{mL}$ ), followed by centrifugation (1500 rpm for 15 minutes). The resulting supernatant liquid was used for the study. Solutions in an amount of $10 \mu \mathrm{L}$ were applied with an automatic dispenser into appropriate sectors on the surface of a Petri dish with nutrient media, on which the cultures of microorganisms at a concentration of $10^{9} \mathrm{~b} / \mathrm{mL}$ have been previously uniformly distributed. The antimicrobial effect was evaluated based on the presence and size of the lysis zone.

For a quantitative assessment of the antimicrobial effect of aqueous solutions, we were adding $100 \mu \mathrm{L}$ of samples under study to $1 \mathrm{~mL}$ of a one-day old liquid bacterial culture. The samples were incubated for 24 hours at a temperature of 37 oC with further inoculation on the surface of the medium (MPB) in a Petri dish sensu the conventional Gould's technique [15]. Quantitative seeding was determined by the number of colony-forming units (CFU) in the inoculations after the incubation. MPB culture supplemented with $100 \mu \mathrm{L}$ of sterile saline served as a control. All studies were carried out in repetitions.

\section{Identification of chemical composition in natural minera samples}

$\mathrm{X}$-ray diffraction and $\mathrm{X}$-ray fluorescence analyses of minerals were carried out using the DRON-6 diffractometer ( $2 Q$ from 1 to 30; step 0.05; 1 degree per $\mathrm{min}$ ) and the D2 PHASER powder diffractometer (Brucker) at the KBSU Center for Collective Equipment Use.

\section{Statistical data processing}

Statistical significance was calculated using Student's t-test. In tables and graphs, data are presented as mean \pm standard deviation.

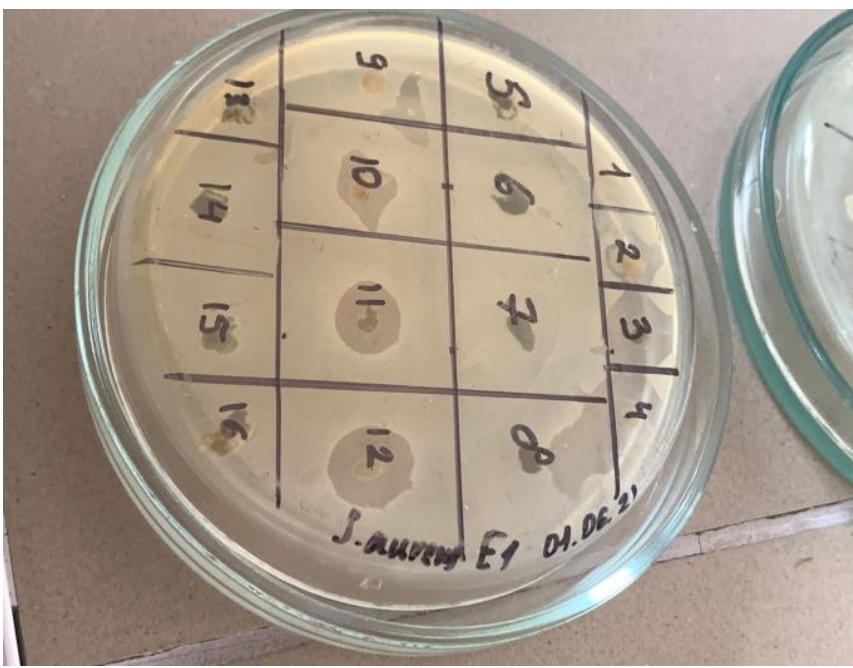

Figure 1. Antibacterial effect of pastes prepared from calcium (light clay) and sodium (dark clay) montmorillonites of Gerpegezh deposit in KBR on Staphylococcus aureus strain.

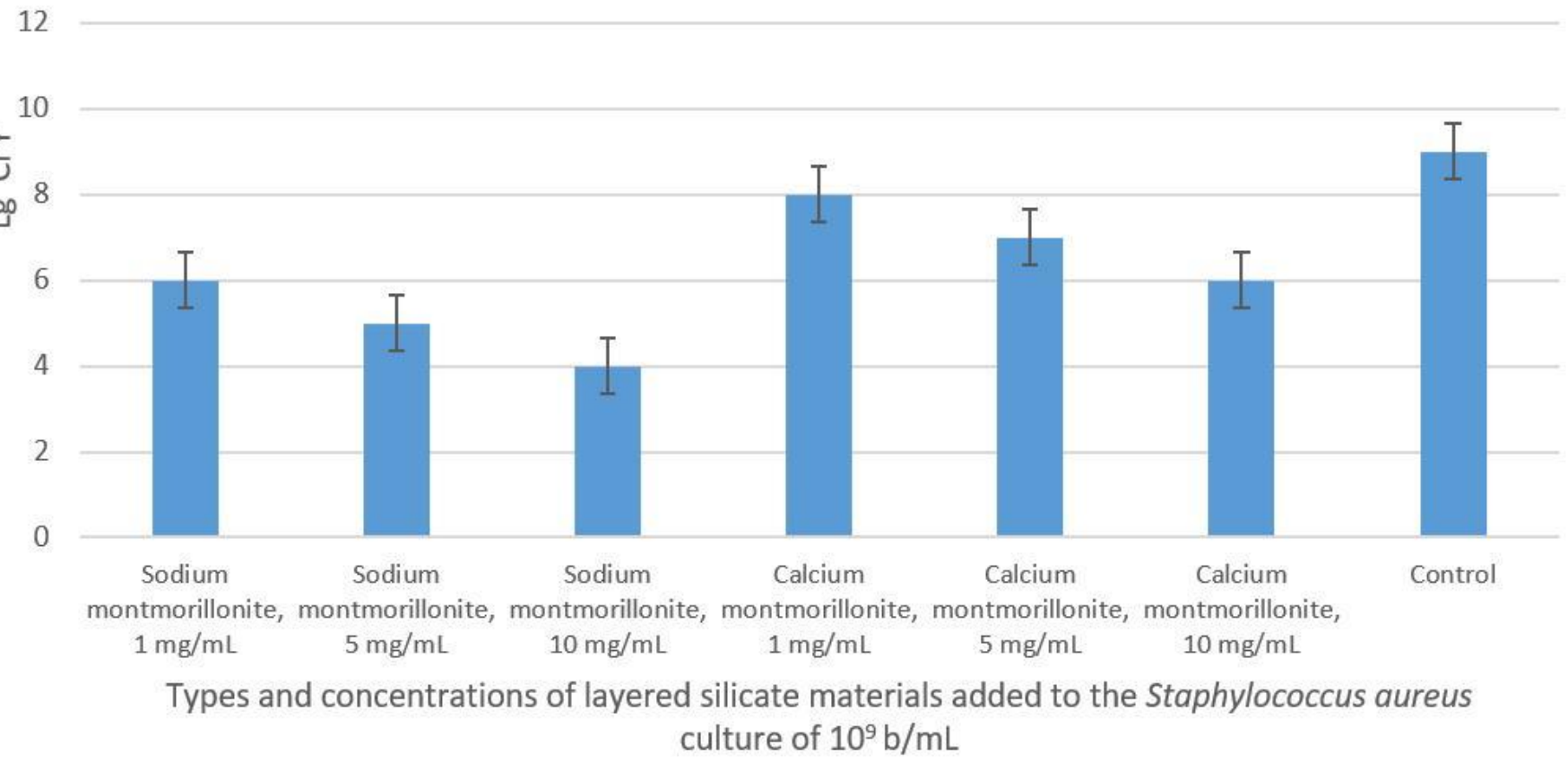

Figure 2. Quantitative results of evaluating antibacterial effect of layered silicate samples of Gerpegezh deposit on Staphylococcus aureus strain, (log CFU). 


\section{Results}

Experiments on investigating the antimicrobial effects of pastes prepared from natural minerals made it possible to establish that ammonite, montmorillonite of Azerbaijani origin, and serpentinite did not have a direct antimicrobial effect on the studied cultures of bacteria and fungi (S. aureus, E. coli, C. albicans). At the same time, the growth of $S$. aureus was suppressed by calcium and sodium montmorillonites from the Gerpegezh deposit in Kabardino-Balkarian Republic (KBR) (Figure 1). These samples did not affect the cultures of $E$. coli and yeast-like fungi.

At the next stage, the antimicrobial properties of aqueous solutions of the samples under study were examined. As can be seen from the data presented in Table 1, antibacterial effect on $S$. aureus strain was exhibited by solutions of Gerpegezh layered silicate materials, and a dose-dependent effect was revealed. To investigate the stability of the antimicrobial action of the watersoluble samples, the antibacterial effect was assessed immediately after the preparation of solutions and after 24,48 and 72 hours. As shown in Table 1, the lysis zones were identified regardless of the exposure time of the solutions; the diameter of the lysis zones of the solutions did not change statistically significantly as well.

To quantify antibacterial action of the samples, CFU number was determined in the inoculations after incubation with solutions of different concentrations.

For all samples shown in Figure 2, $p<0.05$ relative to the control. Also, it is clear that sodium montmorillonite exhibits the greatest antibacterial effect $(p<0.05)$, and its dose-dependence is revealed.

The main substances of which layered silicate materials are composed are silicon dioxide and aluminum oxide (Table 2).

According to the data of X-ray fluorescence analysis, in the structure of dark Gerpegezh clay, the samples of which had a more pronounced anti-staphylococcal effect, trivalent iron and oxides of manganese and titanium predominate, $p<0.05$.

\section{Discussion}

Our study results implied the possibility of using natural minerals of various origins as antimicrobial agents. Bentonite clays are valuable mineral raw materials. In terms of consumption volume, the most important areas of bentonite clay application in Russia are metallurgy, agriculture and medicine [13, 14]. The empirical use of clays has often led to a good wound healing effect [16]. By now, both individual samples and their modified forms are studied. However, the sensitivity of microorganisms to layered silicate materials varies. In one of the studies, the treatment with clay suspension and filtrate resulted in a statistically significant reduction in the biofilm population of only gram-negative bacteria [17]. In some published sources, natural minerals were used in a modified form [18, 19]. Silver halides in montmorillonite were obtained by dispersion in the dark. Powder X-ray diffraction showed the intercalation of $\mathrm{AgCl}$ and $\mathrm{AgBr}$ nanoparticles into the interlayer space of the clay. Antibacterial activity was investigated against gram-positive and gram-negative bacteria. The antibacterial effect on S. aureus and E. coli decreased in the order: $\mathrm{AgCl}$-montmorillonite $>\mathrm{AgBr}$ - montmorillonite $>\mathrm{Agl}-$ montmorillonite. No antibacterial activity of these samples against Pseudomonas aeruginosa strains was found [18].
Another example of a new composite antibacterial material $\mathrm{ZnO} / \mathrm{Cu}^{2+}$-chitosan/ montmorillonite (ZCCM) was obtained using montmorillonite as a carrier, $\mathrm{Zn}(\mathrm{Ac})_{2} \bullet 2 \mathrm{H}_{2} \mathrm{O}, \mathrm{Cu}\left(\mathrm{NO}_{3}\right)_{2} \bullet 3 \mathrm{H}_{2} \mathrm{O}$ and chitosan as raw materials [20]. The antibacterial activity of ZCCM against $E$. coli, Salmonella typhimurium and $S$. aureus was assessed by the minimum inhibitory concentration, minimum bactericidal concentration and the effect of growth curves. ZCCM exhibits high antibacterial activity, which is higher than ZnO-montmorillonite, $\mathrm{Cu}^{2+}$-montmorillonite and $\mathrm{ZnO} / \mathrm{Cu}^{2+}$-montmorillonite.

The antibacterial effect appears to be dependent on the unique complex and ratio of various inorganic substances in each sample. In our study, it is shown that ammonite, montmorillonite of Azerbaijani origin and serpentinite did not have any antimicrobial effect on any of the studied microbial cultures. An antibacterial dose-dependent effect was found in montmorillonite of Gerpegezh origin (sodium and calcium montmorillonites) towards S. aureus but no effect whatsoever was discovered towards E. coli and C. albicans (Table 1, Figure 1). Sodium montmorillonite demonstrated a stronger anti-staphylococcal effect, compared with calcium montmorillonite (Table 1). The results of assessing the chemical composition of natural materials, using contemporary X-ray methods revealed a difference in the concentration of oxides of manganese, iron and titanium in samples of sodium and calcium montmorillonites of Gerpegezh origin, which was associated with the geological conditions of their formation, dynamic transformations in the soil, structural features and characteristics of their overall mineral composition.

As it turned out, some of the data presented in the literature indicated the antibacterial effect of iron-containing samples [11, 21]. For example, in the study by Qin C., et al, the antibacterial activity of montmorillonite saturated with $\mathrm{Fe}^{3+}$ was investigated using urban wastewater. The bacterial decontamination efficiency (loss of bacterial viability) was $92 \pm 0.64 \%$ when the secondary wastewater was mixed with $\mathrm{Fe}^{3+}$-saturated montmorillonite for 30 minutes and then increased to $97 \pm 0.61 \%$ after 4 hours. Nearly all (99.9\%) E. coli and enterococci in the secondary wastewater were deactivated when the water was exposed to $\mathrm{Fe}^{3+}$-saturated montmorillonite for 1 hour [11]. One of possible action mechanisms is the suppression of microbial growth by trivalent iron via the formation of hydroxyl free radicals. Pure trivalent iron is not an inhibitor of bacterial growth; it manifests itself as an antimicrobial compound due to the reduction of $\mathrm{Fe}^{3+}$ to $\mathrm{Fe}^{2+}$ with the formation of hydroxyl free radicals, which have a strong indiscriminate sterilization ability [22]. However, these data did not explain the selective activity against gram-positive staphylococci and the absence of the effect of mineral complexes against $E$. coli. One of the possible explanations for the different effects of natural iron-containing complexes on gram-positive and gram-negative microflora is associated with different ways of transporting iron in gram-negative and gram-positive bacteria [23]. The results of Qi Chen, et al confirmed that microbial inactivation was mainly due to $\mathrm{Fe}^{3+}$ in relation to gram-positive bacteria. On the other hand, living microorganisms can actively neutralize oxidative stress both in the environment and in the host organism, adapting through the induction of antioxidant protective enzymes.

\section{Conclusion}

Our study has illustrated the possibilities and limitations of using various samples of layered silicate minerals for the production of antibacterial solutions. The spectrum of 
antimicrobial activity largely depends on the unique composition of mineral complexes. Samples with a high content of iron(III) can be considered promising for the development of natural antimicrobial remedies.

\section{Funding}

The study was conducted within the framework of the Public Procurement of the Ministry of Science and Higher Education of the Russian Federation, No. 0669-2020-0008.

\section{Conflict of Interest}

The authors declare no conflicts of interest.

\section{References}

1. Reis AC, Kolvenbach BA, Nunes O, Corvini PFX. Biodegradation of antibiotics: The new resistance determinants - part II. N Biotechnol 2020; 54: 13-27. https://doi.org/10.1016/j.nbt.2019.08.003.

2. Breijyeh Z, Jubeh B, Karaman R. Resistance of gram-negative bacteria to current antibacterial agents and approaches to resolve it. Molecules 2020; 25(6): 1340. https://doi.org/10.3390/molecules25061340.

3. Ghosh D, Veeraraghavan B, Elangovan R, Vivekanandan P. Antibiotic resistance and epigenetics: More to it than meets the eye. Antimicrob Agents Chemother 2020; 64(2): e02225-19. https://doi.org/10.1128/aac.02225-19.

4. Lerminiaux NA, Cameron ADS. Horizontal transfer of antibiotic resistance genes in clinical environments. Can J Microbiol 2019; 65(1): 34-44. https://doi.org/10.1139/cjm-2018-0275.

5. Kranz J, Wagenlehner FME, Schneidewind L. Complicated urinary tract infections. Urologe A 2020; 59(12): 1480-1485. German. https://doi.org/10.1007/s00120-020-01343-1.

6. Wong DW. Carriage of antibiotic resistant bacteria flora and its role in the guidance of clinical decision making. Pathog Dis 2020; 78(5): ftaa030. https://doi.org/10.1093/femspd/ftaa030.

7. Messina NL, Williamson DA, Robins-Browne R, Bryant PA, Curtis N. Risk factors for carriage of antibiotic-resistant bacteria in healthy children in the community: A systematic review. Pediatr Infect Dis J 2020; 39(5): 397-405. https://doi.org/10.1097/inf.0000000000002532.

8. Hamouche E, Sarkis DK. Evolution of susceptibility to antibiotics of Escherichia coli, Klebsiella pneumoniae, Pseudomonas aeruginosa and Acinetobacter baumanii, in a University Hospital Center of Beirut between 2005 and 2009. Pathol Biol (Paris) 2012; 60(3): e15-e20. French. https://doi.org/10.1016/j.patbio.2011.03.011

9. Pottinger PS. Methicillin-resistant Staphylococcus aureus infections. Med Clin North Am 2013; 97(4): 601-619. https://doi.org/10.1016/j.mcna.2013.02.005

10. Zaitsev AA. Community-acquired pneumonia: diagnostic, treatment and vaccine prevention opportunities in the context of the COVID-19 pandemic. Practical Pulmonology 2020; (1): 14-21. Russian. https://www.elibrary.ru/item.asp?id=43863884.

11. Qin C, Chen C, Shang C, Xia K. Fe ${ }^{3+}$ - saturated montmorillonite effectively deactivates bacteria in wastewater. Sci Total Environ 2018; 622-623: 88-95. https://doi.org/10.1016/j.scitotenv.2017.11.302.

12. Pan Y, Gao Y, Hu J, Ye G, Zhou F, Yan C. Montmorillonite nanosheets with enhanced photodynamic performance for synergistic bacterial ablation. J Mater Chem B 2021; 9(2): 404-409. https://doi.org/10.1039/d0tb02254c.

13. Belousov PE, Pokidko BV, Zakusin SV, Krupskaya VV. Quantitative methods for quantification of montmorillonite content in bentonite clays. Georesources 2020; 22(3): 38-47. Russian. https://doi.org/10.18599/grs.2020.3.38-47.

14. Belousov PE, Krupskaya VV. Bentonite clays of Russia and neighboring countries. Georesources 2019; 21(3): 79-90. Russian. https://doi.org/10.18599/grs.2019.3.79-90.
15. Gould JC. Quantity and quality in the diagnosis of urinary tract infections. Br J Urol 1965; 37: 7-12. https://doi.org/10.1111/j.1464 410x.1965.tb09567.x.

16. Liu C, Liu C, Yu S, Wang N, Yao W, Liu X, et al. Efficient antibacterial dextran-montmorillonite composite sponge for rapid hemostasis with wound healing. Int J Biol Macromol 2020; 160: 1130-1143. https://doi.org/10.1016/j.ijbiomac.2020.05.140.

17. Caflisch KM, Schmidt-Malan SM, Mandrekar JN, Karau MJ, Nicklas JP, Williams LB, et al. Antibacterial activity of reduced iron clay against pathogenic bacteria associated with wound infections. Int J Antimicrob Agents 2020; 52(5): 692-696. https://doi.org/10.1016/i.ijantimicag.2018.07.018.

18. Sohrabnezhad Sh, Rassa M, Mohammadi Dahanesari E. Spectroscopic study of silver halides in montmorillonite and their antibacterial activity. J Photochem Photobiol B 2016; 163: 150-155 https://doi.org/10.1016/j.jphotobiol.2016.08.018.

19. Semlali Aouragh Hassani FZ, El Bourakadi K, Merghoub N, Qaiss AEK, Bouhfid R. Effect of chitosan/modified montmorillonite coating on the antibacterial and mechanical properties of date palm fiber trays. Int $J$ Biol Macromol 2020; 148: 316-323. https://doi.org/10.1016/j.ijbiomac.2020.01.092.

20. Ma X, Gao L, Ma Y, Zhang X. Antibacterial activity and mechanism of $\mathrm{ZnO} / \mathrm{Cu}^{2+}$ - chitosan/montmorillonite. J Wuhan Univ Technol Mater Sci Ed 2021; 36(4): 510-516. https://doi.org/10.1007/s11595-021-2438-2.

21. Krewulak KD, Vogel HJ. Structural biology of bacterial iron uptake. Biochim Biophys Acta 2008; 1778(9): 1781-1804. https://doi.org/10.1016/j.bbamem.2007.07.026.

22. Sun $H Q$, Lu XM, Gao PJ. The Exploration of the Antibacterial Mechanism of FE(3+) against Bacteria. Braz J Microbiol 2011; 42(1): 410-414. https://doi.org/10.1590/s1517-83822011000100050.

23. Chen $Q$, Li J, Wu Y, Shena F, Yao M. Biological responses of Grampositive and Gram-negative bacteria to nZVI $\left(\mathrm{Fe}^{0}\right), \mathrm{Fe}^{2+}$ and $\mathrm{Fe}^{+}$. RSC Adv 2013; 3: 13835-13842. https://doi.org/10.1039/C3RA40570B.

\section{Authors:}

Madina Kh. Shpagina - Undergraduate Student, Institute of Dentistry and Maxillofacial Surgery, Kabardino-Balkarian State University, Nalchik, Russia. https://orcid.org/0000-0002-9283-7128.

Umalat I. Dugarov - Undergraduate Student, Institute of Dentistry and Maxillofacial Surgery, Kabardino-Balkarian State University, Nalchik, Russia. https://orcid.org/0000-0003-2775-1210.

Seda S. Khashirova - Researcher, Center for Advanced Materials and Additive Technology, Kabardino-Balkarian State University, Nalchik, Russia. https://orcid.org/0000-0003-1948-1687.

Amina S. Vindizheva - PhD, Senior Researcher, Center for Advanced Materials and Additive Technology, Kabardino-Balkarian State University, Nalchik, Russia. https://orcid.org/0000-0002-4050-8947.

Elena B. Barokova - PhD, Associate Professor, Department of Microbiology, Virology and Immunology, School of Medicine, KabardinoBalkarian State University, Nalchik, Russia. https://orcid.org/0000-00024807-4186.

Larisa B. Tlapshokova - DSc, Professor, School of Medicine, KabardinoBalkarian State University, Nalchik, Russia. https://orcid.org/0000-00018564-1242.

Svetlana Yu. Khashirova - DSc, Professor, Chair of the Department of Organic Chemistry and Macromolecular Compounds, Kabardino-Balkarian State University, Nalchik, Russia. https://orcid.org/0000-0002-72101252.

Zaira F. Kharaeva - DSc, Professor, Chair of the Department of Microbiology, Virology, and Immunology, School of Medicine, KabardinoBalkarian State University, Nalchik, Russia. https://orcid.org/0000-00032302-2491. 